\title{
A GEOMORFOLOGIA GEOGRÁFICA ENQUANTO PRODUTO DAS RELAÇÕES ENTRE A ESTÉTICA E A METAFÍSICA DA MATÉRIA
}

\author{
GEOMORPHOLOGY AS A PRODUCT OF GEOGRAPHICAL RELATIONS BETWEEN AESTHETICS \\ AND METAPHYSICS OF MATTER \\ GEOMORFOLOGÍA GEOGRÁFICA COMO PRODUCTO DE LAS RELACIONES ENTRE LA ESTÉTICA \\ Y LA METAFÍSICA DE LA SUSTANCIA
}

\author{
Antônio Carlos Vitte - Unicamp - Campinas - Brasil \\ vitte@uol.com.br
}

\begin{abstract}
Resumo
Esse trabalho argumenta que a geomorfologia geográfica é o produto de um complexo intercruzamento entre as descobertas da história da Terra e as transformações filosóficas sobre a natureza e a arte. A união das descobertas e dos avanços na ciência newtoniana com a pintura de paisagem, fundamentadas em uma concepção de espaço, permitiram a representação do relevo e, a partir dele, as investigações sobre a geologia e as formações estratigráficas. 0 maior impulso para o surgimento da geomorfologia geográfica foi dado pelas reflexões sobre a morfologia desenvolvidas por Goethe, que influenciou os wenerianos e a descoberta dos processos formadores do relevo.
\end{abstract}

Palavras-chave: Geomorfologia. Arte. Matéria. Metafísica da natureza. Geologia. Processos.

\begin{abstract}
This paper argues that the geographical geomorphology is the product of a complex intercrossed between discoveries in Earth's history and the changing philosophical about the nature and art. The union of the discoveries and advances in science Newtonian with the painting of landscape, based on a conception of space, have the representation of relief from it and the research on the geology and stratigraphic formations. However, the greatest impetus for the emergence of geographical geomorphology, were reflections on the morphology, developed by Goethe,
\end{abstract} which influence the processes of discovery by wenerians.

Key words: Geomorphology. Art. Metaphysics of nature. Geology. Processes. Mapping.

\section{Resumen}

Este documento sostiene que la geomorfología geográfica es el producto de un complejo entramado entre los descubrimientos de la historia de la Tierra y el cambio filosófico sobre la naturaleza y el arte. La unión de los descubrimientos y avances de la ciencia de Newton con la pintura de paisaje, sobre la base de una concepción del espacio, permite la representación de socorro y, a partir de sus investigaciones sobre la geología y las formaciones estratigráficas. El mayor impulso para el surgimiento de la geomorfología geográfica fue dado por las reflexiones sobre la morfología desarrollada por Goethe, que influyó en la wenerianos y el descubrimiento de los procesos de formación de lo reilevo.

Palabras clave: Geomorfologia. Arte. La matéria. Metafísica de la naturaleza. Geologia. Procesos. 


\section{Introdução}

Até o século XVIII, a natureza era concebida apenas como um exercício da razão e cujo fenômeno poderia ser explicado pela dedução dos princípios constituintes da metafísica aristotélica. A partir do século XVIII a natureza passa a ganhar status de independência, particularmente a partir dos trabalhos de Newton, onde o mecanicismo começa a impor uma separação entre a metafísica e a ciência da natureza. A metáfora da natureza-máquina impulsiona o surgimento da história natural e a separação epistêmica entre as várias disciplinas, tais como a zoologia, a botânica e a geologia. É nesse contexto surgirá a geografia física, enquanto disciplina que promoverá a integração das disciplinas em processo de fragmentação epistêmica e a validação metafísica da superfície da Terra enquanto unidade temática e ontológica.

O surgimento da geografia física será o responsável pela derrocada da teologia natural, com a expulsão das explicações escolásticas sobre o funcionamento da natureza. No entanto, esse processo não é simples e linear, pois a transição do século XVIII para o início do XIX é marcado por um vacuum epistêmico e filosófico, provocado pelo próprio mecanicismo, levando os filósofos, teólogos, artistas e cientistas a refletirem sobre a natureza e o seu processo formativo. É nesse momento, que mediado pela filosofia kantiana, pela naturphilosophie, pela biologia e pela estética de Goethe, donde emergirá a geomorfologia geográfica.

O objetivo desse trabalho é demonstrar que a geomorfologia geográfica é o produto de um complexo processo de reflexão sobre a superfície da Terra, onde a morfologia, inicialmente concebida como produto do dilúvio, passará, lentamente, a ser concebida como um sublime, portanto estético, de organização e dinâmica do cosmos que se materializa nas formas da Terra.

\section{Matéria e forma: o substrato metafísico da geografia física}

A estruturação lógica e epistemológica da geografia física resulta de um profundo debate em torno da metafísica da natureza (VITTE, 2007), onde os conceitos de matéria, força e causalidade são problematizados e permitem a constituição de princípios que regem as ciências e a explicação do mundo empírico. Aqui, a concepção de matéria é fundamental para se pensar a causalidade e a partir de um substrato metafísico, qualificar as 
forças e os objetos naturais. É a partir desse posicionamento filosófico que se constrói a representação da natureza e de suas formas, sendo assim, podemos dizer que o conceito de matéria é uma construção racional, onde a geografia física se constitui como uma explicação racional e metafísica da natureza.

Queremos dizer, que, no processo de constituição da modernidade, a qualificação metafísica da matéria pela geografia física é fundamental para o estabelecimento das bases interpretativas sobre a história da natureza, pois o conceito de matéria fica alocado no espaço e no tempo, permitindo assim, não apenas o conhecimento das relações causais e mecânicas, como por exemplo, os processos erosivos, mas também o estabelecimento de leis transcendentais, universais, como o zoneamento morfo-bio-climático, que permite a compreensão sobre o funcionamento da natureza enquanto uma totalidade dinâmica, materializada em uma escala regional e/ou local.

Sob o ponto de vista da metafísica aristotélica e retrabalhada tanto pela escolástica quanto pela naturphilosophie, a matéria [Stoff] deve ser compreendida como um substrato metafísico, que se materializa em formas [Form].

Essa qualificação acontece devido a um retrabalhamento da naturphilosophie romântica e transcendental (LENOIR, 1981), motivados pela filosofia kantiana e não concordando com as explicações sobre o funcionamento da natureza e a abordagem matemática para a explicação dos fenômenos naturais, procurou requalificar os conceitos de matéria, força e causalidade; donde derivou uma volta aos estudos aristotélicos, mediados pelas filosofias de Platão, Kant, Leibniz e Spinoza.

A geografia física e, a geomorfologia, em particular, surge a partir de um esforço em conceber o desenvolvimento de uma nova noção de matéria, para que com isso fosse elaborada uma nova metafísica da natureza. Para tanto, há uma volta a filosofia de Aristóteles, basicamente para a sua noção de forma substancialis, que foi desenvolvida pelos filósofos da escolática (HÜBSCHER, 1982), que servia para se pensar o princípio interno de todas as propriedades da natureza. A noção escolástica de forma substanciallis, remetia a noção de matéria prima, ou seja, uma matéria sem forma [Materie], sem qualidade, geratriz das formas accidentalis [Stoff], as formas empíricas mediadas pela razão e pela contemplação estética. Para Bloch (1977) a noção de matéria de Aristóteles remete ao princípio da potentia e entelékia do mundo, o princípio que rege o processo, a transformação da matéria e por consequência, a constituição das formas empíricas no mundo, segundo uma teleologia. Segundo Mollowitz (1985) a noção de matéria, na naturphiloso- 
phie adquire dois significados, que se complementam e formam uma totalidade orgânica, além de fundamentar os estudos empíricos e redimensionar o papel da mensuração da natureza, com o desenvolvimento da cartografia, o outro lado do conceito de matéria fundava-se na noção de ideia platônicaagostiniana-kantiana de forma, que fundamentava as ciências da natureza na modernidade, na medida em que limitou os fenômenos ao espaço e ao tempo, dando um sentido prático e objetivo aos fenômenos da natureza. Para nós, a noção de ideias, remete apenas a um esquema prático de pensamento e não a uma doutrina, pois essa noção foi útil para se ultrapassar o conceito kantiano de coisa-em-si, o que permitiria posteriormente, o desenvolvimento de conceitos como os de paisagem e de geoesfera.

Esse procedimento, o da noção de ideia, permite a harmonização da razão e da estética, além de conceber a matéria como uma totalidade orgânica, livre de qualidade, que será transformada ao longo dos tempos e segundo arranjos específicos, sendo assim plasmada em formas e arranjos morfológicos específicos, mas integrados por um novo princípio mecânico de causalidade e por uma energéia aristotélica (BLOCH, 1977), que durante os séculos XVII e XVIII foi conceituado como influxo material.

Na naturphilosophie transcendental (LENOIR, 1981) a matéria foi conceituada como sendo a união do espaço e do tempo, que aparecem como multiplicidade de coexistência e de sucessão, sendo que espaço e tempo constituem o princípio da individualização da matéria em formas particulares.

Para Schelling (1856-1861) que exerceu forte influência na metafísica da natureza na naturphilosophie (RICHARDS, 2002) e, em Darwin (VITTE, 2009), a matéria assim concebida, é a base da filosofia da identidade, onde ideal e real, física e metafísica, formam uma totalidade. A objetivação, ou seja, a realização da matéria [Materie] em forma accidentallis, em forma empírica, que seria o objetivo da ciência e da geografia física em particular.

A partir desse corolário, podemos dizer que a geografia física se constitui e passaria a trabalhar com uma nova metafísica da matéria, promovendo a invenção da natureza e de sua regionalização na modernidade. Pois, o fenômeno da geografia física e da geomorfologia, em particular, no caso, a forma de relevo, seria produzido a partir de uma articulação entre a matéria, a unidade e a multiplicidade.

Assim, as formas são determinadas no espaço e no tempo, que guia a construção da representação, donde se poderia intuir a causalidade da matéria e sua sucessão (JANAWAY, 1999). Assim, a matéria seria o conteúdo das formas, que por sua vez atuariam na sensibilidade, pois preenchem o 
espaço e o tempo. Nesse novo princípio de matéria e forma, desenvolvido pela naturphilosophie, a causalidade não seria apenas uma relação entre o espaço e o tempo, mas o produto de uma conjunção entre eles, que se espacializa em morfologias distintas ou em conjuntos homogêneos de uma dada morfologia. Esse princípio foi aplicado para as formações florestais, para a classificação zoológica, e para a distinção de zonas geomorfológicas, cuja matriz foram os trabalhos de Alexander von Humboldt, que permitiram o desenvolvimento da abordagem regional para os fenômenos da natureza e, acima de tudo, um procedimento epistêmico e metodológico, que levou a configuração das zonalidades morfo-bio-climáticas da superfície da Terra (VITTE, 2007; 2008).

Do século XVIII até meados do século XIX, coincidindo com os trabalhos de Alexander von Humboldt (1764-1859) e Carl Ritter (1769-1859), espaço e tempo passaram a ser concebidos como exigência necessária para a matéria, donde o movimento foi concebido como processo de construção do espaço e do tempo, a partir da transformação das formas. O processo espaço-temporal, ou seja, a transformação da forma, é a demonstração da causalidade que se realiza na construção de novos arranjos morfológicos, que, por sua vez ativam a sensibilidade e nos permitem conhecer o espaço.

Seja no plano da estética, portanto da sensibilidade, ou da ciência, com a mensuração e a representação cartográfica e matemática das formas, a matéria, foi considerada uma substância, portadora de qualidades e que permite representar a mudança, a sucessão e a transformação de um lugar ou região. Pois, as formas são acidentes da matéria, que se transforma e assume diferentes manifestações (relevo, clima, vegetação, animais, por exemplo), portanto, sujeita a mudanças, e, que se ligam pela simultaneidade, pela duração e pela causalidade que liga o espaço ao tempo.

Assim, ficava explicada a diversidade da vida (MAYR,1982), onde o teleológico e o estético influenciavam a criação de um novo sentido de matéria e de sua realização na superfície da Terra, donde surgirá a geografia física e a geomorfologia. O conceito de matéria, agora, metafisicamente requalificado, exercerá uma dupla função, pois permitirá tanto os avanços no campo da física, da biologia e da geografia (FRERCKS, WEBER \& WIESENFELDT, 2009; MAYR, 1982; RICHARDS, 2002). O novo conceito de matéria permitirá, também, a qualificação estética da forma, que exercerá influência na pintura de paisagem e na cartografia, para Alexander von Humboldt, arte que poderia ser utilizada como um instrumento técnico de investigação da natureza e de educação das pessoas (RICOTTA, 2003). 


\section{A representação da forma}

Segundo Pimenta (2007), coube ao conde de Shaftesbury (1671-1713), que viveu na Inglaterra pós-revolução gloriosa, dominada pelo empirismo e pelo sensualismo; o início da problematização das relações entre a arte, a filosofia e a ciência. A busca pela universalidade entre o ideal da representação dos objetos naturais, já fortemente trabalhados pelo mecanicismo e o papel das belas-artes, fizeram com que Shaftesbury se preocupasse em buscar uma harmonia e uma unidade na natureza. Para o conde, essa harmonia poderia ser representada pelo desenho, em que o ajuste entre a forma e o conteúdo conduziria a consideração do desenho das formas e de suas relações, como uma linguagem, cuja função seria a de transmitir o sentimento universal de prazer.

Shaftesbury (PIMENTA, 2007, p. 16) retomando o conceito platônico de forma, procurou dar um status para as artes plásticas, particularmente para o desenho, uma vez que o mesmo poderia articular a unidade das formas, por meio de uma regra, permitindo ao observador transmitir o conhecimento sobre aquela realidade empírica retratada. Assim, em meados do século XVII e início do século XVIII, desenvolve-se a noção de que há uma linguagem das formas, construída pela relação entre arte, ciência e estética, que permitirá o remanejamento de conceitos até então desenvolvidos e/ou melhorados com a filosofia empírica, cujo marco é a teoria do gosto de Burke (1729-1797), que exercerá forte influência na Crítica do Juízo de Imannuel Kant, publicada em 1790. O campo da estética é delimitado com Burke, por meio dos conceitos de belo e sublime; assim como é resguardada a independência da natureza em relação à subjetividade humana (BURKE, 1993).

Essa passagem da forma, enquanto uma entidade natural, para o domínio da sensibilidade e o reino das artes, garantirá de um lado a construção de uma filosofia da arte e a redefinição do campo da estética como um campo filosófico e com fortes influências na pesquisa científica, como é o caso da Crítica do Juízo de Kant (KANT, 1995), mas também garantirá o desenvolvimento da pesquisa científica, por meio da representação da natureza, onde o conceito de paisagem natural será epistemologicamente significativo para a construção das ciências da natureza e da geografia física, nas mãos de Alexander von Humboldt.

Para o Kant da Crítica do Juízo, impacto pelo empirismo inglês e pelos relatos dos viajantes, a forma é muito complexa pois, ao mesmo tempo que está ligada ao domínio da estética, mais especificamente ao domínio do 
gosto, implica também em uma concepção de conteúdo. Ou seja, a forma guarda tanto uma disposição estética, quanto uma racional, que é imediata e sensível, devendo ser articulada em uma explicação universal, que é o conceito de natureza (KANT, 1995).

A forma, para Kant (KANT, 1995) não é apenas uma figura, mas abrange também um jogo de sensações no espaço e no tempo. Desse jogo, resultam os arranjos de sensações, dado por um jogo de figuras, cores, sons. Para Kant, a forma é tanto material quanto imaterial, sendo o fundamento do prazer, um juízo universal, que permitirá a sistematização dos objetos naturais e o seu agrupamento ao redor de uma unidade, que para Kant, é dado pelo sentimento de beleza. Monta-se assim, as bases para o conceito geográfico de paisagem, que será desenvolvido na naturphilosophie, por Goethe e Humboldt (VITTE, 2008).

A estética e o racional, garantiriam a independência do objeto, que pode ser percebido e submetido a leis empíricas que explicam como eles se formam e são percebidos. Para Kant (KANT, 1995) e posteriormente será desenvolvido por Goethe e Humboldt, o arranjo dos objetos naturais e a sua disposição ao prazer, é dado pela imaginação, que em um livre jogo entre o entendimento e a imaginação, produzirá um estado harmonioso entre os objetos, que para Schelling (1856-1861), a unidade e a harmonia seriam alcançadas com o uso da intuição intelectual. Ainda para Schelling (1856-1861) essa formulação kantiana possibilitou o desenvolvimento de uma poesia da natureza, onde o conceito de matéria, como formulado na dedução transcendental (KANT, 1982), permitirá a incorporação do equilíbrio dinâmico e da dialética entre atração e repulsão na geração das formas.

Para Schelling (1856-1861) haveria uma alma cósmica que produziria a união entre os objetos naturais e ao mesmo tempo garantiria a produtividade da natureza. Essa produtividade e o desenvolvimento dos objetos naturais seriam garantidos por constantes polaridades e metamorfoses, que produziriam a bela natureza. Para nós está aí uma pista interessante para estudarmos o conceito de paisagem na geografia e o de forma de relevo na geomorfologia.

\section{Goethe e a poiesis orgânica: construção a geomorfologia geográfica}

O maior herdeiro e ao mesmo tempo revolucionário da naturphilosophie é Goethe, que irá imprimir um toque especial na mesma, a medida 
em que sairá da mística de Schelling (RICHARDS, 2002), mas manterá uma visão panteísta de natureza, mesclada com a necessidade da matematização e da experimentação dos processos naturais. Para Goethe, o problema do mecanicismo de Descartes e Newton era a tentativa de redução do universo a poucas leis universais e acima de tudo, por considerá-lo estático. Para Goethe, seguindo Spinoza e Leibniz, a matéria seria dinâmica, devendo o cientista-artista apreender o processo formador do mundo, plasmador da forma. Segundo Cassirer (1994, p. 113), essa concepção foi construída a partir dos trabalhos de Buffon, que introduziu os estudos históricos na natureza, que conduzirá Goethe a noção de metamorfose (WINTER, 2001, p. 195).

Para Goethe, a natureza é um conjunto de forças plasmadoras, que pode ser compreendida a partir do entendimento de seus próprios princípios. Para isso é necessário uma metodologia científica e um paradigma estético e filosófico. A premissa de Goethe é que os fenômenos naturais devem ser entendidos a partir de uma visão processual e morfológica, para saber como as formas se realizam. Para Cassirer (1994, p. 121) essa é a demonstração de uma forte influência de Shaftesbury na construção de uma nova estética da natureza em Goethe e que influenciará a sua pesquisa sobre a natureza. Para Winter (2001) as discussões de Shaftesbury conduziram Goethe a buscar o entrelaçamento entre estética, filosofia da natureza e literatura, onde a natureza deixará de ser considerada como um grande relógio para ser concebida como um organismo, composto por estruturas energéticas.

Goethe desenvolverá uma abordagem orgânica e sistêmica nos estudos da natureza, que garantirá a unidade da natureza na multiplicidade de seus fenômenos e objetos. Há uma constante mudança na natureza, responsável pela variedade de formas, pois a natureza é devir e ao mesmo tempo potência.

Essa posição de Goethe é garantida pela postura metafísica de que a dinâmica da natureza é dada pela polaridade entre forças criadoras e destruidoras. A ideia de polaridade é inseparável da ideia de unidade, de tal forma que o mundo é uma teia inter-relacional. Para tal, deve-se realizar intensas observações e investigações sobre a natureza. Essa fase de Goethe, é marcada pelos seus trabalhos nas minas de Ilmenau nas cercanias de Weimar, intensificada pela sua viagem à Itália, com o encontro da planta primordial (Urpflanze) e a formulação de seu artigo sobre a Metamorfose das Plantas (1790), culminando, segundo o próprio Goethe, com a elaboração da Doutrina das Cores (1808-1810) (MEYER, 1967). 
Em 1776, Goethe inicia os seus trabalhos em Ilmaenau, estudando mineralogia, geologia, botânica e química. Esses estudos apontam para uma nova visão de natureza, adquirida pela observação objetiva, que resultou no poema "Die Natur", que segundo Korff (1951, p. 199) exerceu forte influência na filosofia e na ciência alemã.

A partir de agora, para Goethe, a natureza é dinâmica e constantemente gera novas formas. O princípio morfológico aparece para Goethe como matriz de um permanente processo de mudança, sempre regido pelas mesmas leis, mas renovado pela criação de novas formas, onde domina o princípio espinosiano da extensão. A singuralidade da forma é a possibilidade de observação e investigação da totalidade. A multiplicidade da natureza é a demonstração do processo da totalidade, cabendo ao observador perceber a polaridade na constituição das particularidades da natureza, como uma proposta metodológica para se representar a totalidade.

Para Goethe, a matéria seria o arquétipo das formas, que por sua vez, são transformadas em proto-formas (Urformem) e geram os reinos da natureza, como o granito, o animal, ou a planta primordial.

É desse princípio epistêmico e estético, que Goethe irá desenvolver o desenho da paisagem e suas partes, para depois reconstruir o todo e assim apreender o singular e ao mesmo tempo compreender a evolução do todo.

Die wenigen Linien, die ich aufs Papier zielhe, oft übereilt, selten richtig, erleichtern mir jede Vorstellung von sinnlichen Dingen, den man erhebt sich ja eher zum Allgemeinen, wenn man die Gegenstände genauer un schärfer betrachtet. (Goethe; Italienische Reise, S. 268. DB 4: Goethe, S. 11452, vgl. Goethe-HÁ Bd. 11, S. 173)

A pesquisa sobre a forma e sua relação com a totalidade, a paisagem, para se estabelecer a singularidade do fenômeno, em Goethe, ocorre a partir do entrecruzamento entre o olhar, o desenhar e o pesquisar, que está, a nosso ver, na gênese dos estudos de geomorfologia, geologia, anatomia e botânica. Havia em Goethe a vontade de abarcar o estudo a unidade da natureza de uma forma geral. Donde haveria um diálogo tenso entre a força de criação da natureza e a do artista-cientista no registro das formas e da totalidade-em-forma.

Haveria uma unidade fundamental nos fenômenos da natureza, um entrelaçamento entre formas simples e complexas, um constante processo de transformação que acarreta modificação das formas. O processo é a parte integradora e formadora da natureza, a morfologia é a bildung da natureza, mantendo uma visão integrada e ao mesmo tempo geral. Isso garantia a 
Goethe a passagem das formas singulares à visão sistêmica da natureza, garantida pelo processo de polaridade.

A matéria e a forma são um vir-a-ser, dinâmica e estética. O que garante a Goethe essa segurança metafísica, é a paisagem que se transforma. A Terra passa a ser vista como uma arte, podendo ser representada e estuda pelo desenho, pela pintura, possibilitando uma nova interação com o espaço, mediada pelo metafísico e pelo empírico. Há uma relação recíproca entre as formas geológicas, botânicas, climáticas e geomorfológicas, gerando a paisagem; que permitiria ser desenhada e reunida sob o signo do belo (GOETHE, S 11248, vgl. GOETHE-HA Bd, 11, S.47).

Em Goethe há o encontro da estética, da filosofia do olhar e de uma nova concepção de ciência. Estava criada assim, a geomorfologia. A ciência da síntese da natureza e do cosmos, produto da integração harmoniosa do todo.

A bildung da natureza levaria a produção de novas formas, havendo uma conexão entre os objetos da natureza em uma visão de totalidade.

A forma denotaria em Goethe um sentido plástico, portanto estéticocientífico-metafísico da transformação da matéria, requalificada pela naturphilosophie, levando a criação da ciência da morfologia, inaugurando assim, a possibilidade de, ao mesmo tempo, realizar-se o estudo das estruturas e formas da natureza como também uma arte em consonância com os princípios orgânicos encontrados na natureza.

Rapidamente a ciência da morfologia transforma-se em geomorfologia, onde impera polaridade entre a subjetividade e a objetividade, e, o conceito de paisagem é o cimento epistêmico que permite o jogo entre o transcendental e o empírico.

Essa concepção de Goethe foi fortemente influenciada pela noção de sublime conforme registrado na Crítica do Juízo de Kant e pela influência de Rickertt sobre a pintura da paisagem.

Em Goethe, ocorrerá uma fusão entre paisagem e arte, que impulsionará a pesquisa científica sobre a história da Terra, onde a geomorfologia será concebida como a integradora da natureza. Nesse papel, o conceito de sublime será fundamental, assim como o conceito de experiência estética de Schiller, que influenciará Humboldt e os naturalistas na descoberta das paisagens tropicais. 


\section{A geologia, a estética e a forma de relevo como produto da história da terra}

Até o presente momento, procuramos demonstrar que a história da geomorfologia e da geografia física como um todo, resultou de uma complexa relação multi-causal e multi-temporal, o que desautoriza um pesquisador menos afeito à história de sua ciência a atribuir a geomorfologia e a geografia física, um desenvolvimento linear, fundamentado em uma causalidade simplória. A gênese da geomorfologia e da geografia física está lastreada em um profundo debate metafísico sobre a natureza e sua diversidade na superfície da Terra. É a partir de uma mutação epistêmica, com a descoberta e a problematização filosófica da horizontalidade, que ocorre a invenção da superfície da Terra.

É somente a partir das reflexões metafísicas de Kant sobre o espaço e os trabalhos de Buffon (1708-1788), que se inicia a construção da história da Terra, que levará a criação da geomorfologia. Mas para isso, foi necessária a requalificação metafísica dos conceitos de matéria e forma, a partir do intercruzamento de três críticas metafísicas. A primeira é a crítica de Buffon ao sistema de classificação de Carl Linnaeus (1707-1778), considerada a primeira grande classificação do mundo natural que ocorreu após a física newtoniana e, que abriu espaço para a construção da história natural. A segunda crítica desenvolveu-se a partir da requalificação e transformação do conceito renascentista de natureza e matéria, que foi utilizada para criticar o mecanicismo cartesiano-newtoniano. E finalmente, a terceira e mais bem estruturadas de todas as críticas, mas que também incorporou as demais, foi construída por Leibniz (1679-1759) e por seus discípulos, principalmente o filósofo alemão Christian Wolff (1679-1716), que exerceu forte influência em Kant e nos filósofos da naturphilosophie, como Schelling e Goethe (SLOAN, 1990).

A crítica leinbniziana sobre o conceito newtoniano de espaço (VITTE, 2007), trouxe fortes implicações empíricas, que associadas aos trabalhos de Leibniz em história natural, levou à construção da noção de protogea (SLOAN, 1990, p. 303), onde a história da Terra é interpretada a partir de uma concepção dinâmica e produto de relações de organismos e processos ecológicos que ocorrem a partir de interrelações espaço-temporais.

Estava montada assim, as bases metafísicas para a construção da história natural e a construção da geomorfologia, cabendo a Buffon o início do processo de construção da história natural, agora, não mais fundamentada em um sistema abstrato, como o de Linnaeus, mas baseada no conhecimento físico das relações e dos processos naturais. A ordem espaço-temporal 
ficava agora subjugada a uma dinâmica e a uma história cosmológica, onde geologia e biologia poderiam ser apreendidas a partir da observação da sucessão causal dos fenômenos, inclusive os catastróficos, que abriam espaço para a construção de uma teoria da Terra (SLOAN, 1990, p. 304). Para Buffon as espécies biológicas, assim como a geologia, eram entidades físicas, que possuíam uma história que era construída a partir de relações espaçotemporais. Ou seja, a natureza é produzida por causação material e possui um processo histórico, que leva a transformação das formas, a migração geográfica dos animais e das plantas.

Com o retrabalhamento metafísico da noção de espaço e o despertar para a existência da materialidade da natureza, estavam erigidas assim, as bases para a construção de uma história natural, onde a concepção de espaço e localização seriam fundamentais para a invenção da geologia e da geomorfologia.

Para Rachel Laudan (1982; 1990) é justamente no período de 1780 a 1840 que ocorre a construção da ciência da geologia e da geomorfologia. Para a autora (LAUDAN, op. cit) a gênese dessa construção situa-se no debate entre netunistas e plutonistas. No entanto, gostaríamos de acrescentar, que esse debate possibilitou a criação da ciência geológica e da geomorfologia, pois os mesmos foram fundamentados pela discussão sobre a existência de uma história da natureza em contraposição a técnica da descrição da natureza, como foi inicialmente desenvolvida por Kant e, que segundo Herder e Forster, era uma concepção dogmática sobre o desenvolvimento da natureza (VITTE \& SILVEIRA, 2009), pois não considerava a possibilidade de transformação histórica da matéria e das formas, pois a sua classificação de ciência fundamentava-se em Linneaus.

A partir dessas críticas, Kant praticamente aceita a possibilidade de uma ciência genética da natureza e ao mesmo tempo resguardando validade para a Naturgeschichte para a forma do atualismo. Admitindo assim, a existência de uma variação no grau de analogias entre o passado e o presente, a partir da observação dos processos causais que sustentariam uma ciência histórica da natureza segundo a tradição Buffon-Herder.

Kant passa a admitir o transformismo histórico das formas e com as críticas de Forster, e repensa o seu sistema de classificação das ciências, onde a Naturgeschichtge passa a ter o mesmo status que a Naturbeschreibung, e, onde sob o ponto de uma nova epistême, a descrição da natureza passa a ser concebida como ciência, a geografia física, que, agora, articula-se a um grande sistema, que é a história da natureza. 
A entrada da concepção teleológica levou Kant a definir a natureza como uma unidade sistemática que possui uma função no domínio do julgamento reflexivo. A natureza passa a ser tomada como totalidade (Inbergriff) de objetos e formas, uma Naturwissenschaft, que dentro do juízo reflexivo pode ser considerada como uma Naturlehre, mantendo assim uma unidade entre a descrição e a história da natureza. Nesse jogo, Kant é levado a desenvolver a noção de arqueologia da natureza, concepção considerada importante para se entender complexa vida orgânica e as transformações de suas formas.

Outra influência importante para o surgimento da geologia e da geomorfologia, a nosso ver, foram os trabalhos de Blumembach com a anatomia comparada auxiliariam no desenvolvimento do método comparativo de Cuvier levando-o a descoberta da paleontologia enquanto registro da história material da Terra e da Vida (RUDWICK, 1976).

O método da anatomia comparada de Cuvier, propiciou a construção de leis e princípios e forneceram evidências sobre a história da Terra, levando-o a assumir por princípio, o atualismo, para entender as modificações das formas dos animais, quando da comparação de um fóssil com um possível descendente vivo (RUDWICK, 1976, p. 115-116).

Esse contexto científico e epistemológico, associado as discussões dos wenerianos sobre o papel das águas superficiais no modelamento do relevo e na constituição dos estratos geológicos, conduziu à criação do conceito de formação geológica e de história deposicional (LAUDAN, 1982). Ainda segundo Laudan (1990), os wenerianos foram os responsáveis não somente pela criação da geologia histórica, mas também pela geologia causal, na medida em que para reconstruir a história da Terra e de determinadas feições geomorfológicas, como as montanhas e o relevo karst, passaram a desenvolver o raciocínio da correlação e comparação entre formações geológicas, com dados da paleontologia e da mineralogia. No caso das montanhas, os wenerianos passaram a utilizar esquema explicativo causal, como desenvolvimento da teoria da elevação de massas de terra, amplamente desenvolvida por Alexander von Humboldt quando de sua viagem à América. Em outros casos, como para explicar o abaixamento do relevo, utilizaram da transformação mineral (intemperismo químico), como no caso do relevo karst, mais especificamente das dolinas (LAUDAN, 1990, p. 320).

Em pleno século XVIII haverá a confluência entre as descobertas geológicas, os relatos dos viajantes e o aparecimento da arte da representação da paisagem, que levarão ao desenvolvimento da geomorfologia. Essa con- 
fluência ocorrerá a partir do desenvolvimento da estética, particularmente a partir da qualificação do sublime por Kant na Crítica do Juízo em 1790.

Desde o século XVII os pintores de paisagem, como Hackert, vinham preocupando-se com o desenho e a pintura das montanhas. Inicialmente para demonstrar o poder da criação de deus e o papel do dilúvio na esculturação da superfície da Terra, mas no século XVII, já sob o domínio do mecanicismo, as pinturas de montanhas, como os Alpes, passaram a descrever os minerais, os acamamentos, as rupturas e as diferenças altimétricas nos sistemas montanhosos. Abria-se assim, através da pintura topográfica da paisagem, a possibilidade de estudos comparativos sobre as paisagens, as montanhas e a geologia.

A estética, por meio do sublime, abria a possibilidade de estudos sobre a história da Terra e descobria-se o relevo, como produto do desenvolvimento material da natureza, a partir da concepção de múltiplas transformações e o papel da água na esculturação dessas formas, fato que os wenerianos já vinham chamando à atenção.

Nesse momento, o destaque é para Horace-Bénédict de Saussure (1740-1799) que segundo Klonk (2003), foi um dos pioneiros nos estudos geomorfológicos nos Alpes, onde observou que as formas de relevo dependiam da história da Terra e, que a formação do relevo envolvia múltiplos e complexos eventos. Para Saussure (KLONK, 2003, p. 599), o registro das formas, dos processos e dos agentes, por meio da pintura e da paisagem era fundamental para o desenvolvimento do conhecimento científico e para a metodologia de realização de experimentos.

A pesquisa científica, para Saussure (KLONK, 2003, p. 600) deveria ser fundamentada em trabalho de campo, onde o pesquisador deveria levar consigo vários instrumentos de medidas, um pintor de paisagem ou desenhista, onde deveria ser metodicamente registrado os eventos e ao mesmo tempo, a pintura da paisagem, os croquis, os blocos diagrama, propiciariam a noção de todo e o sublime da cena, despertaria a curiosidade científica.

A montanha passou a ser concebida como um arquivo da natureza, a chave para se entender a história e a transformação da Terra. É o caso de Goethe, que em 1777, no escrito “On Granite” defende que a montanha e a geologia registram uma história, que poderia ser representada em secções esquemáticas e em perfis topográficos.

Para a escolha das melhores secções temáticas o geomorfólogo deveria guiar-se pelo sublime topográfico, em que a beleza da paisagem representava a história da natureza. A geomorfologia assim, possui sua gênese a 
partir de um complexo debate que se estabeleceu entre a história natural e a estética. Mas essa formação foi propiciada por um intenso debate metafísico sobre a matéria e sua transformação em formas e morfologias.

Atualmente, não muito distante desse debate, obviamente que resguardando os tempos e as complexidades, o que se coloca hoje, sobre a geomorfologia geográfica, em um contexto de transformações e mutações do mundo e da Terra, exige não apenas uma discussão pragmática, mas filosófica e epistêmica sobre o papel da geomorfologia e da geografia física na construção de um discurso espacial sobre a natureza. Quem sabe se não estamos passando por um momento de crise, com a gestação de um novo mundo e a necessidade de requalificarmos novamente a matéria o sentido da geografia e da geomorfologia no mundo?

\section{Referências}

BLOCH, E. Das materialismus-Problem, seine Geschichte und Substanz. Frankfurt am Main, Suhrkamp, 1977.

BURKE, E. Uma investigação filosófica sobre a origem de nossas idéias do sublime e do belo. Campinas: Papirus/Ed. Unicamp, 1993.

CASSIRER, E. A filosofia do iluminismo. Campinas: Ed. da Unicamp, 1994.

FRERCKS, J., WEBER, H. \& WIESENFELDT, G. Reception and discovery: the nature of Johann Wilhelm Ritter's invisible rays. Studies in History and Philosophy of Science, (www.elsevier. com/locate/shpsa), 2009.

GOETHE-HANDBUCH. Editado por Bernd Witte ert al. 6 vols. Stuttgart, Weimar: Metzler, 1996.

HÜBSCHER, A. Denken Gegen den Strom-Schopenhauer: gestern, heute, morgen. Bonn, Bouvier Verlag, 1988.

JANAWAY, C. (Org.) The Cambridge companion to Schopenhauer. London: Cambridge University Press, 1999.

KORFF, H. Geist der Goethezeit. Versuch einer ideellen Entwicklung der Klassich-romantischen literatujrgeschichte. Leipzig: Koehler \& Amelang, 4, Auf, 1958.

KLIONK, C. Science, art and representation of the natural world. In: PORTER, R. (Ed.) The Cambridge history of science, vol. 4, Cambridge: Cambridge University Press, 2003, p. 584-618.

LAUDAN, R. From mineralogy to geology. The foundations of a science, 1650-1830. Chicago: Chicago University Press, 1982.

. The history of geology, 1780-1840. In: OLBY, R. C., CANTOR, G. N., CHRISTIE, J. R. R. \& HODGE, M. J. S. (Org.) Companion to the history of modern science. London: Routledge, 1990, p. 314-326. 
MAYR, Ernst. The Growth of biological thought. Cambridge: Harvard University Press, 1982.

MEYER, H. (Org.) Goethe. Das Leben im Werk. Stuttgart: HansE. Günther Verlag, 1967.

PIMENTA, Pedro P. G. A linguagem das formas. Natureza e Arte em Shaftesbury. SP: Alameda, 2007.

RICHARDS, Robert J. The romantic conception of life. Chicago and London: Chicago University Press, 2002.

RICOTTA, Lúcia. Natureza, ciência e estética em Alexander von Humboldt. RJ: Mauad, 2003.

RUDWICK, Martin. Bursting the limits of time: the reconstruction of geohistory in the age of revolution. Chicago: University of Chicago Press, 1976.

SCHELLING, F. W. J. Einleitung zu dem Entwurf eines Systems der Naturphilosophie. I. In:__ Sämmtliche Werke (SW), Edição de K.F.A. Schelling, Sttutgart, Cotta, 18561861.

SLOAN, P.R. Natural history, 1670-1802. In: OLBY, R. C., CANTOR, G. N., CHRISTIE, J. R. R. \& HODGE, M. J. S. (Org.) Companion to the history of modern science. London: Routledge, 1990, p. 278-295.

VITTE, Antonio C. Da metafísica da natureza à gênese da geografia física moderna. In: VITTE, Antonio C. (Org.) Contribuições à história e à epistemologia da geografia. RJ: Bertrand Brasil, 2007, p. 11-47.

. Da ciência da morfologia à geomorfologia geográfica: uma contribuição à história do pensamento geográfico. Mercator, vol. 7, n. 12, 2008, p. 113-120.

. Da teleologia da natureza ao darwinismo: mutações e possibilidades interpretati-

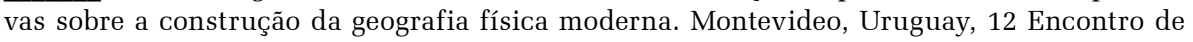
Geógrafos de América Latina-EGAL.TrabalhoCompleto. (Documento disponível em htpp:// egal2009.easyplanners.info/buscar.php), 2009, p. 1-15.

WINTER, U. Naturphilosophie und naturwisschenschaften., IN: GLASER, H. A. (Org.) Wende von der Aufklärung zur romantic, 1760-1820. Philadelphia: John Benjamins Publishing Company, 2001, p. 173-208.

Antonio Carlos Vitte - Professor do departamento de Geografia e do Programa de Pós-Graduação em Geografia da Unicamp, SP. 